\title{
Analysis of the differences in structural chromosomal aberrations of the gastric mucosa between $H$. pylori positive and negative gastric cancer patients: Involvement of $H$. pylori in the onset of gastric cancer and examination of the mechanism in gastric carcinogenesis following $\mathrm{H}$. pylori eradication
}

\author{
TADASHI OHARA ${ }^{1}$, JUNJI KASANUKI ${ }^{2}$, HISAAKI OHARA $^{3}$, YUHSAKU KANOH $^{4}$, HIDEKAZU SUZUKI $^{5}$, \\ HIROSHI HASHIMOTO ${ }^{6}$, TOSHIMI CHIBA ${ }^{7}$, TETSUO MORISHITA ${ }^{1}$ and TOSHIFUMI HIBI ${ }^{5}$ \\ ${ }^{1}$ Department of Internal Medicine, Tokyo Dental College, Chiba 261-8502; ${ }^{2}$ Department of Gastroenterology, \\ Tokyo Women's Medical University, Yachiyo Medical Center, Chiba 276-0046; ${ }^{3}$ Division of Orthodontics \\ and Dentfacial Orthopedics, Department of Oral Growth and Development, Ohu University, School of \\ Dentistry, Fukushima 963-8611; ${ }^{4}$ Department of Laboratory Medicine, Kitasato University, School of \\ Medicine, Kanagawa 228-8555; ${ }^{5}$ Department of Internal Medicine, Keio University, School of Medicine, \\ Tokyo 160-8502; ${ }^{6}$ Department of Geriatrics, JR Tokyo General Hospital, Tokyo 151-8528; ${ }^{7}$ The First \\ Department of Internal Medicine, Iwate Medical University, School of Medicine, Iwate 020-8505, Japan
}

Received June 2, 2006; Accepted July 24, 2006

\begin{abstract}
Gene mutations are essential to carcinogenesis. If an evident difference is observed in gastric mucosal chromosomal structure aberrations between $H$. pylori (Hp)-negative and Hp-positive gastric cancer patients, it may be interpreted as suggesting the involvement of $\mathrm{Hp}$ in gene mutations. This study was undertaken to compare chromosomal structural aberrations between Hp-negative and Hp-positive gastric cancer patients and to evaluate the effects of Hp eradication on chromosomal structures in clinical cases. The subjects of this study were 40 patients with gastric cancer divided into four groups: Group A was composed of 12 patients with Hpnegative gastric cancer (well-differentiated gastric cancer in 5 cases and poorly-differentiated in 7 cases), Group B of 8 patients with $\mathrm{Hp}$-negative gastric cancer following $\mathrm{Hp}$ eradication (well-differentiated in 4 case and poorlydifferentiated in 4 cases), Group C of 13 patients with Hppositive gastric cancer (well-differentiated in 7 cases and poorly-differentiated in 6 cases) and Group D of 7 patients with gastric cancer (well-differentiated in 5 cases and
\end{abstract}

Correspondence to: Dr Tadashi Ohara, Department of Internal Medicine, Tokyo Dental College, 1-2-2 Masago Mihama-Ku, Chiba 261-8502, Japan

E-mail: tohara@tdc.ac.jp

Key words: loss of heterozygosity, microsatellite instability, structural chromosomal aberration, gastric cancer, $H$. pylori infection poorly-differentiated in 2 cases) undergoing $\mathrm{Hp}$ eradication at subtotal gastrectomy. In each of the groups A, B and C, the structural chromosomal aberration such as loss of heterozygosity (LOH) and microsatellite instability (MSI) was analyzed. In Group D, changes in structural chromosomal aberrations after $\mathrm{Hp}$ eradication as compared to the preeradication structures were also analyzed. LOH and MSI were examined by PCR, using DNA extracted from the canceraffected and intact gastric mucosal tissue specimens from each patient. In A, B and C groups, structural chromosomal aberrations were noted, and these aberrations tended to be more marked in cases of poorly-differentiated gastric cancer in each group. In terms of structural chromosomal aberrations, there was no marked difference between Group A and either Group $\mathrm{B}$ or $\mathrm{C}$. Hp eradication resulted in no change in chromosomal structure as compared to the pre-eradication structure in Group D. These results suggest the possibility that Hp eradication does not affect chromosomal structures and Hp is involved in gastric carcinogenesis as an additive environmental factor rather than as a factor acting at the gene level.

\section{Introduction}

One important factor regarding the genes responsible for carcinogenesis is structural chromosomal aberrations. All cancer tissues have some structural chromosomal aberrations (1-7). We had examined H. pylori (Hp)-positive gastric cancer patients for structural chromosomal aberrations such as loss of heterozygosity ( $\mathrm{LOH}$ ) and microsatellite instability (MSI) and showed changes in the chromosomal structure to be more marked in cases with poorly-differentiated than in those with well-differentiated gastric cancer (8). Various studies have been 
LOH

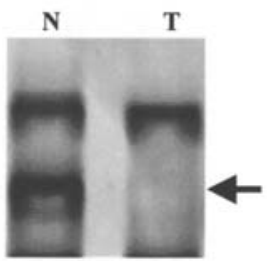

D5S82

(5q15-q23)
MSI

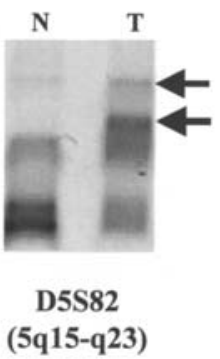

INF

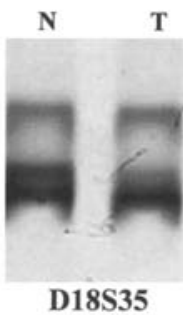

(18q21.1-q21.3)
NI

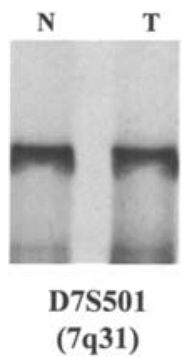

Figure 1. PCR gel electrophoresis. LOH, MSI, INF and NI indicates loss of heterozygosity, microsatellite instability, informative and non-informative, respectively. $\mathrm{N}$ and T indicates normal DNA and tumor DNA, respectively. Arrowhead indicates structural chromosomal aberrations as LOH or MSI.

conducted concerning the relationship between Hp infection and gastric cancer, demonstrating the high probability that $\mathrm{Hp}$ infection is involved in the onset of gastric cancer (9-13), however, the involving site of $\mathrm{Hp}$ infection in gastric carcinogenesis remains unknown. A number of cases of gastric cancer occurring after $\mathrm{Hp}$ eradication have been reported (14-16), and the evaluation of $\mathrm{Hp}$ eradication therapy for a prevention against gastric cancer onset is unknown. Factors responsible for carcinogenesis can be roughly divided into genetic and environmental (17-19). If a difference in structural chromosomal aberration is found between Hp-negative and Hp-positive gastric cancer patients, it may be interpreted as suggesting the involvement of $\mathrm{Hp}$ as a factor inducing gene mutations in carcinogenesis. If no evident difference in structural chromosomal aberrations is found between $\mathrm{Hp}$-negative and $\mathrm{Hp}$-positive gastric cancer cases, it would suggest that $\mathrm{Hp}$ is involved in carcinogenesis as an additive environmental factor which works with gene mutations. In other words, we can say that the analysis of differences in structural chromosomal aberrations between Hp-positive and Hp-negative gastric cancer cases is clinically significant since it may allow us to evaluate the role played by $\mathrm{Hp}$ in gastric carcinogenesis (either as a genetic or an additive environmental factor). Although $\mathrm{Hp}$ eradication has been attempted in many cases as a means of preventing the onset of gastric cancer, there are no studies dealing with the effects of eradication on chromosomal structures. If eradication affects the chromosomal structures, the validity of eradication therapy itself may be questioned.

The present study was undertaken to examine structural chromosomal aberrations in Hp-negative gastric cancers and Hp-negative gastric cancers occurring following $\mathrm{Hp}$ eradication in comparison to those in $\mathrm{Hp}$-positive gastric cancers in clinical cases, and to examine the influence of $\mathrm{Hp}$ eradication for chromosomal structures. Therefore, we investigated the site involved in $\mathrm{Hp}$ infection in gastric carcinogenesis and to what extent $\mathrm{Hp}$ eradication can suppress gastric cancer onset.

\section{Patients and methods}

The subjects of this study were 40 patients with gastric cancer divided into four groups: Group A was composed of 12 patients with Hp-negative gastric cancer $(7$ males and 5 females with a mean age of 61.7 years; well-differentiated gastric cancer in 5 cases and poorly-differentiated in 7 cases), Group B of 8 patients with Hp-negative gastric cancer developing after $\mathrm{Hp}$ eradication (5 males and 3 females with a mean age of 60.3 years; well-differentiated in 4 cases and poorly-differentiated in 4 cases), Group $\mathrm{C}$ of 13 patients with Hp-positive gastric cancer $(7$ males and 6 females with a mean age of 63.6 years; well-differentiated in 7 cases and poorlydifferentiated in 6 cases) and Group D of 7 patients with gastric cancer ( 5 males and 4 females with a mean age of 62.4 years; well-differentiated in 5 cases and poorly-differentiated in 2 cases) undergoing $\mathrm{Hp}$ eradication at surgical treatment as subtotal gastrectomy. Group D is an examination group whether or not the Hp eradication affects to structural chromosomal aberrations. In each of three the groups A, B and C, structural chromosomal aberrations such as LOH and MSI were analyzed and changes in each group were compared. In Group D, changes of structural chromosomal aberrations after eradication as compared to the pre-eradication structures were analyzed. LOH and MSI were assessed by PCR, using DNA extracted from cancer-affected and intact gastric mucosal tissue specimens endoscopically collected from each patient. $\mathrm{Hp}$ infection was diagnosed based on the results of cultures and the urea breath test (UBT), with subjects testing negative to both judged to be negative for Hp infection. Informed consent was obtained from all the patients prior to the study.

Tissue samples. After obtaining informed consent from individual subjects, sample tissues were taken from canceraffected and cancer-free areas in patients with gastric cancer and from atrophic mucosa and atrophy-free mucosa in patients with chronic gastritis. All samples were divided into two segments; one was frozen immediately after collection and stored at $-80^{\circ} \mathrm{C}$ until extraction of DNA, and the other was fixed in $10 \%$ formalin for pathologic diagnosis. Histopathological diagnosis was performed according to the International Classification of Tumors (20) for gastric cancer patients.

DNA extraction. All patients with gastric cancer had histologically confirmed adenocarcinoma of the stomach. Tumor samples for DNA extraction were checked to ensure that they consisted of $>80 \%$ tumor. DNA extraction was as follows: 
Table IA. PCR primers.

\begin{tabular}{|c|c|c|c|c|}
\hline Markers & Locations & $\begin{array}{l}\text { Size of PCR } \\
\text { products (bp) }\end{array}$ & Sequence of primers & Oncogenes/tumor sup. genes \\
\hline D1S116 & $1 \mathrm{p} 31-\mathrm{p} 21$ & 89-101 & $\begin{array}{l}\text { 5/-TACAAGGCAACCACATAATT-3/ } \\
\text { 5/-CTTTTCCTAATTGTGTGTGT-3/ }\end{array}$ & N-ras \\
\hline D1S159 & $1 \mathrm{p} 32$ & 147 & $\begin{array}{l}\text { 5/-TCCTTTACATAAATCATTGTCGTG-3/ } \\
\text { 5/-CGACTCTGCATTACCTTGATAGC-3/ }\end{array}$ & \\
\hline D1S162 & $1 \mathrm{p} 32$ & 134 & $\begin{array}{l}\text { 5/-GGGGGAAGAAGTCCGAGTAG-3/ } \\
\text { 5/-ATAAGGGGAACAGGTCTGGG-3/ }\end{array}$ & L-myc \\
\hline D1S188 & $1 \mathrm{p} 32$ & $149-173$ & $\begin{array}{l}\text { 5/-AACCAATCAAGGTGCCTGCA-3/ } \\
\text { 5/-TCCCCTAGTGTCCTGGCAG-3/ }\end{array}$ & $\mathrm{p} 18$ \\
\hline MYCL1 & $1 \mathrm{p} 32$ & $140-209$ & $\begin{array}{l}\text { 5/-TGGCGAGACTCCATCAAAG-3/ } \\
\text { 5/-CCTTTTAAGCTGCAACAATTTC-3/ }\end{array}$ & $\square$ \\
\hline D5S346 & $5 q 21-q 22$ & $96-122$ & $\begin{array}{l}\text { 5/-ACTCACTCTAGTGATAAATCGGG-3/ } \\
\text { 5/-AGCAGATAAGACAGTATTACTAGTT-3/ }\end{array}$ & \\
\hline D5S82 & $5 q 15-q 23$ & $169-179$ & $\begin{array}{l}\text { 5/-ATCAGAGTATCAGAATTTCT-3/ } \\
\text { 5/-CCCAATTGTATAGATTTAGAAGTC-3/ }\end{array}$ & APC \\
\hline D5S318 & $5 q 15-q 23$ & $176-188$ & $\begin{array}{l}\text { 5/-TCTAGAGGATCTTCCСТCTT-3/ } \\
\text { 5/-CCATCGOTAGAACTAATTTC-3/ }\end{array}$ & \\
\hline D5S299 & $5 q 15-q 23$ & $156-182$ & $\begin{array}{l}\text { 5/-GCTATTCTCTCAGGATCTTG-3/ } \\
\text { 5/-GTAAGCCAGGACAAGATGACAG-3/ }\end{array}$ & \\
\hline MCC & $5 q 21-q 22$ & $168-176$ & $\begin{array}{l}\text { 5/-CCAATGAAACTTCGCTTTAATCAG-3/ } \\
\text { 5/-GTGGAATTTGTATCATGCTCTG-3/ }\end{array}$ & \\
\hline D7S501 & $7 q 31$ & $163-179$ & $\begin{array}{l}\text { 5/-CACCGTTGTGATGGCAGAG-3/ } \\
\text { 5/-ATTTCTTACCAGGCAGACTGCT-3/ }\end{array}$ & \\
\hline D7S523 & $7 q 31$ & $224-240$ & $\begin{array}{l}\text { 5/-CTGATTCATAGCAGCACTTG-3/ } \\
\text { 5/-AAAACATTTCCATACCACTG-3/ }\end{array}$ & Met \\
\hline D7S486 & $7 q 31$ & $114-146$ & $\begin{array}{l}\text { 5/-AAAGGCCAATGGTATATCCC-3/ } \\
\text { 5/-GCCCAGGTGATTGATAGTGC-3/ }\end{array}$ & PPP1R3 \\
\hline D7S677 & 7q31.2-q31.3 & 278 & $\begin{array}{l}\text { 5/-ATCATTCACTATGGGATAGC-3/ } \\
\text { 5/-GAATTACAAGTCACTCTATACAAAA-3/ }\end{array}$ & \\
\hline D7S522 & $7 q 31$ & $217-229$ & $\begin{array}{l}\text { 5/-GCCAAACTGCCACTTCTC-3/ } \\
\text { 5/-ACGTGTTATGCCACTCCC-3/ }\end{array}$ & \\
\hline
\end{tabular}

Samples were powdered with liquid nitrogen. After they had been spun down to be deposited once, genomic DNAs were added to $1000 \mu \mathrm{l}$ of TNES buffer (10 mM Tris- $\mathrm{HCl}$ (pH 8.0), $150 \mathrm{mM} \mathrm{NaCl}, 10 \mathrm{mM}$ EDTA, $0.1 \% \mathrm{SDS})$ and $30 \mu 1$ Proteinase $\mathrm{K}(100 \mu \mathrm{g} / \mathrm{ml})$, stirred, digested, and incubated in a water-bath overnight at $50^{\circ} \mathrm{C}$. After DNAs had been extracted by phenol-chloroform extraction and refined, they were washed and precipitated with ethanol (21). The concentration of extracted DNA was estimated by a spectrophotometric method, and the samples were kept frozen at $-80^{\circ} \mathrm{C}$. From each DNA sample, $50 \mathrm{ng} / \mu 1$ was used for the template of the polymerase chain reaction (PCR) amplification procedure.
PCR and microsatellite analysis. We used 31 primers corresponding to chromosomal regions known to contain major oncogenes and tumor suppressor genes (N-ras, L-myc, p18, APC, Met, PPP1R3, p53, NF1, BRCA1, Smad2, Smad4/DPC4, DCC, ANA, AML1), namely, 1q, 5q, 7q, 17p, $17 \mathrm{q}, 18 \mathrm{q}$ and $21 \mathrm{q}$. The following 31 primers used were: D1S116, D1S159, D1S162, D1S188, MYCL1, D5S346, D5D82, D5S318, D5S299, MCC, D7S501, D7S523, D7S486, D7S677, D7S522, D17S261, D17S1176, TP53, D17S250, D17S1320, D17S1329, D18S46, DCC, D18S35, D18S38, D18S64, D21S369, D21S236, D21S11, D21S1436 and D21S1254 (Table IA and B). The primers were obtained from 
Table IB. PCR primers.

\begin{tabular}{|c|c|c|c|c|c|}
\hline Markers & Locations & $\begin{array}{l}\text { Size of PCR } \\
\text { products (bp) }\end{array}$ & Sequence of primers & Oncogene & /tumor sup. genes \\
\hline D17S261 & 17p12-p11.1 & $157-171$ & $\begin{array}{l}\text { 5/-CAGGTTCTGTCATAGGACTA-3/ } \\
\text { 5/-TTCTGGAAACCTACTCCTGA-3/ }\end{array}$ & - & Unknown \\
\hline D17S1176 & $17 \mathrm{p} 13.1$ & $95-109$ & $\begin{array}{l}\text { 5/-ACTTCATATACATATCACGTGC-3/ } \\
\text { 5/-TCAATGGAGAATTACGATAGTG-3/ }\end{array}$ & & $\mathrm{p} 53$ \\
\hline TP53 & $17 \mathrm{p} 13.1$ & 103 & $\begin{array}{l}\text { 5/-TTGCCTCTTTCCTAGCACTG-3/ } \\
\text { 5/-CCAAGACTTAGTACCTGAAG-3/ }\end{array}$ & & \\
\hline $\mathrm{D} 17 \mathrm{~S} 250$ & $17 q 11.2-12$ & $151-169$ & $\begin{array}{l}\text { 5/-GGAAGAATCAAATAGACAAT-3/ } \\
\text { 5/-GCTGGCCATATATATATTTAAACC-3/ }\end{array}$ & & NF1 \\
\hline D17S1320 & $17 \mathrm{q} 21$ & 180 & $\begin{array}{l}\text { 5/-ACTTTCCAGAAAATCTCTGCTC-3/ } \\
\text { 5/-CCACGTCTTTTCTGTGTTCC-3/ }\end{array}$ & & BRCA1 \\
\hline D17S1329 & $17 \mathrm{q} 21$ & 170 & $\begin{array}{l}\text { 5/-GACTCTGAAGGTAAAGAGCAA-3/ } \\
\text { 5/-CTCCССTGCCTTGGGAGTAG-3/ }\end{array}$ & & \\
\hline D18S46 & $18 \mathrm{q} 21.1$ & $129-153$ & $\begin{array}{l}\text { 5/-GAATAGCAGGACCTATCAAAGAGC-3/ } \\
\text { 5/-CAGATTAAGTGAAAACAGCATATGTG-3/ }\end{array}$ & & $\begin{array}{l}\text { Smad2 } \\
\text { Smad4/DPC4 }\end{array}$ \\
\hline DCC & $18 \mathrm{q} 21.1-\mathrm{q} 21.3$ & 90 & $\begin{array}{l}\text { 5/-CATCCAAGCACTAACAGG-3/ } \\
\text { 5/-CAACGATGATTATAGGCAAT-3/ }\end{array}$ & & \\
\hline D18S35 & $18 \mathrm{q} 21.1-\mathrm{q} 21.3$ & $104-124$ & $\begin{array}{l}\text { 5/-AGCTAGATTTTTACTTCTCTG-3/ } \\
\text { 5/-CTGGTTGTACATGCCTGAC-3/ }\end{array}$ & & DCC \\
\hline D18S38 & $18 \mathrm{q} 21.3$ & $162-172$ & $\begin{array}{l}\text { 5/-TACACGCTCACACTTCAACC-3/ } \\
\text { 5/-AGGATACAAGTAGTGAGAGC-3/ }\end{array}$ & & \\
\hline D18S64 & $18 \mathrm{q} 21.3$ & $188-208$ & $\begin{array}{l}\text { 5/-ATACTGGTGGTGGTTATACAACAT-3/ } \\
\text { 5/-AAATCAGGAAATCGGCA-3/ }\end{array}$ & & \\
\hline D21S369 & $21 \mathrm{q} 11.1$ & $173-201$ & $\begin{array}{l}\text { 5/-ATGGCCTTGGCTAAATGCTG-3/ } \\
\text { 5/-CTAAGCTGATATGGTAAGTACA-3/ }\end{array}$ & & \\
\hline D21S236 & $21 \mathrm{q} 11.1$ & $104-128$ & $\begin{array}{l}\text { 5/-CCCAAATAAAAAAGAGAACAG-3/ } \\
\text { 5/-CTAAAGAGGACTTCAGAGTAAGG-3/ }\end{array}$ & & ANA \\
\hline D21S11 & $21 \mathrm{q} 21$ & $172-264$ & $\begin{array}{l}\text { 5/-GTGAGTCAATTCCCCAAG-3/ } \\
\text { 5/-GTTGTATTAGTCAATGTTCTCC-3/ }\end{array}$ & & \\
\hline D21S1436 & $21 \mathrm{q} 21$ & 178 & $\begin{array}{l}\text { 5/-AGGAAAGAGAAAGAAAGGAAGG-3/ } \\
\text { 5/-TATATGATGAAAGTATATTGGGGG-3/ }\end{array}$ & $\ldots$ & \\
\hline D21S1254 & $21 \mathrm{q} 22.1$ & 148 & $\begin{array}{l}\text { 5/-AAGAGCCAATTACAGAAAGTCA-3/ } \\
\text { 5/-GTTGTTTTAAGGATGGTCATTC-3/ }\end{array}$ & $\longrightarrow$ & AML1 \\
\hline
\end{tabular}

Research Genetics (Huntsville, AL). PCR amplification was performed in a total reaction volume of $20 \mu \mathrm{l}$, as described previously (22). Each PCR reaction mixture contained $250 \mathrm{ng}$ of sample DNA, 20 pmol of each primer, $10 \mathrm{mM}$ Tris- $\mathrm{HCl}$ (pH 8.3), $50 \mathrm{mM} \mathrm{KCl}, 3.0 \mathrm{mM} \mathrm{MgCl}_{2}, 2 \mathrm{mM} \mathrm{dNTP}$, and 0.5 units of Taq DNA polymerase (Perkin-Elmer Cetus, Norwalk, CT). Thirty-five cycles of denaturation at $94^{\circ} \mathrm{C}$ for $1 \mathrm{~min}$, and extension at $72^{\circ} \mathrm{C}$ for $1 \mathrm{~min}$ were performed with a DNA thermal cycler (Perkin-Elmer Cetus). After dilution with an adequate volume of formamide-dye mixture $(95 \%$ formamide, $20 \mathrm{mM}$ EDTA, $0.05 \%$ bromophenol blue, and
$0.05 \%$ xylene cyanol), the PCR products were heat-denatured $\left(98^{\circ} \mathrm{C}, 5 \mathrm{~min}\right)$, chilled on ice, and electrophoresed on $6 \%$ urea-formamide-polyacrylamide gel at $3 \mathrm{~W}$ for 2-3 h, depending on fragment size. Silver staining of the gels was performed using a DNA silver staining kit (Amersham Pharmacia Biotech AB, Uppsala, Sweden). To ensure reproducibility in each case with $\mathrm{LOH}$ or MSI, all tests were performed under the same conditions.

Assessment of LOH and MSI. LOH in tumor DNA samples was assessed by scanning densitometry and analyzed with 
A

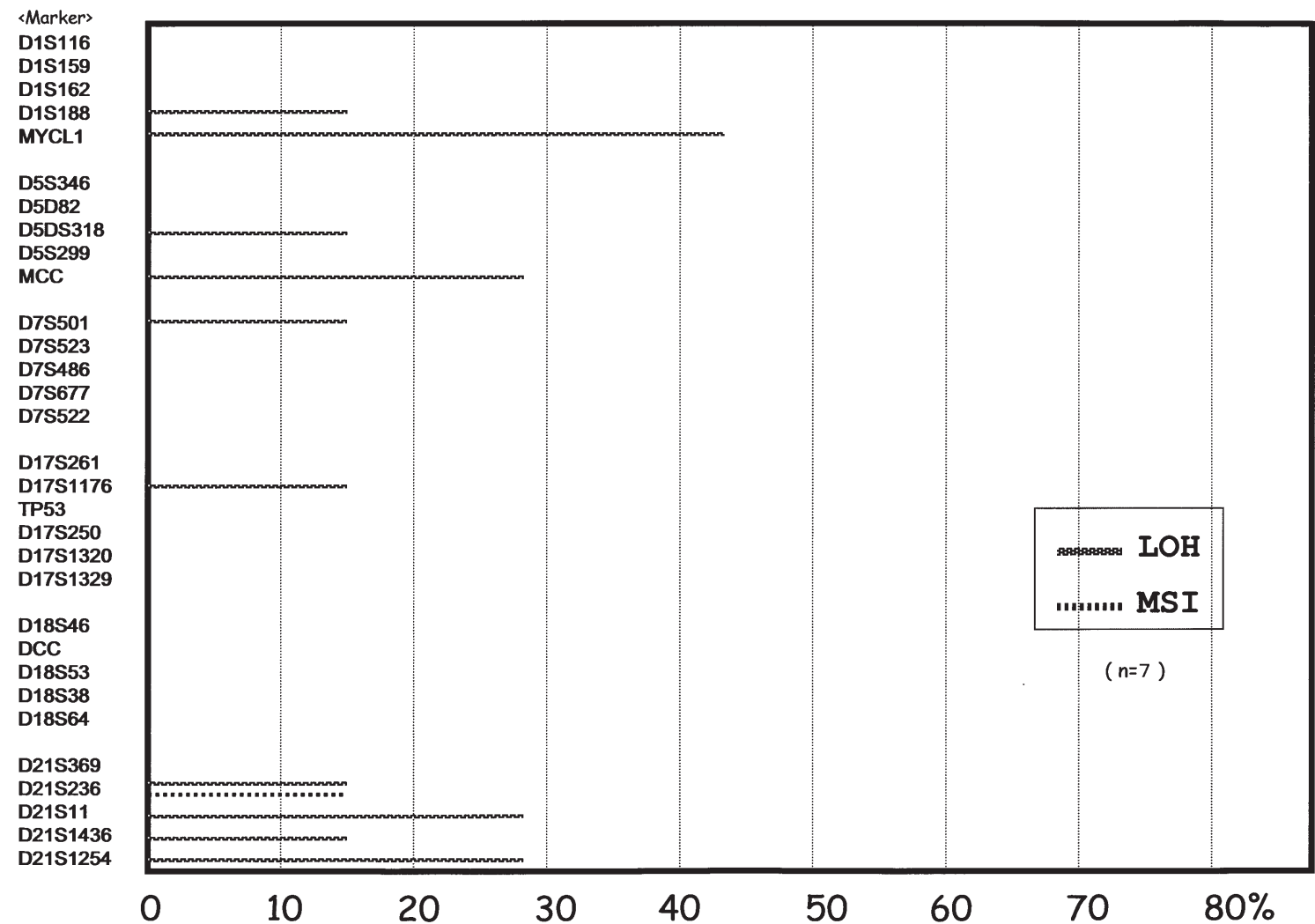

B

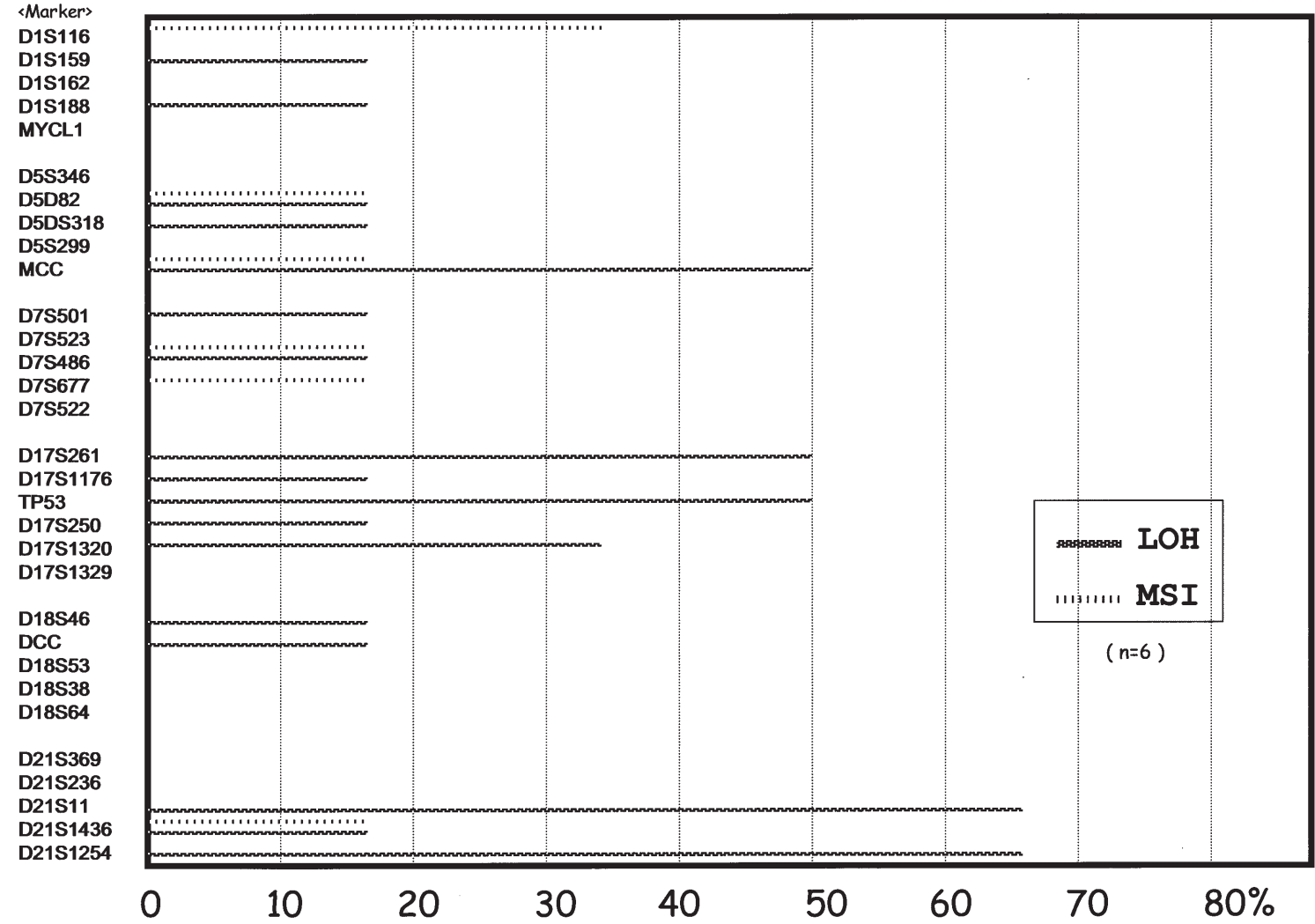

Figure 2. (A) Frequency of the deletion of chromosome 1p, 5q, 7q, 17p, 17q, 18q and 21q in Hp-positive well-differentiated adenocarcinoma with LOH or MSI. (B) Frequency of the deletion of chromosome 1p, 5q, 7q, 17p, 17q, 18q and 21q in H.pylori positive poorly-differentiated adenocarcinoma with LOH or MSI.

National Institute of Health (NIH) software (Image version 1.62, Dr W. Rasband, NIH, Bethesda, MD, USA). Signal intensities in tumor DNA were compared with those of the corresponding normal DNA. A reduction in signal intensity of
$>50 \%$ was required for $\mathrm{LOH}$. Commonly, deleted regions were defined by considering the loci most frequently showing $\mathrm{LOH}$, together with multiple interstitial deletions. MSI in DNA samples was also assessed as positive in cases with 
A

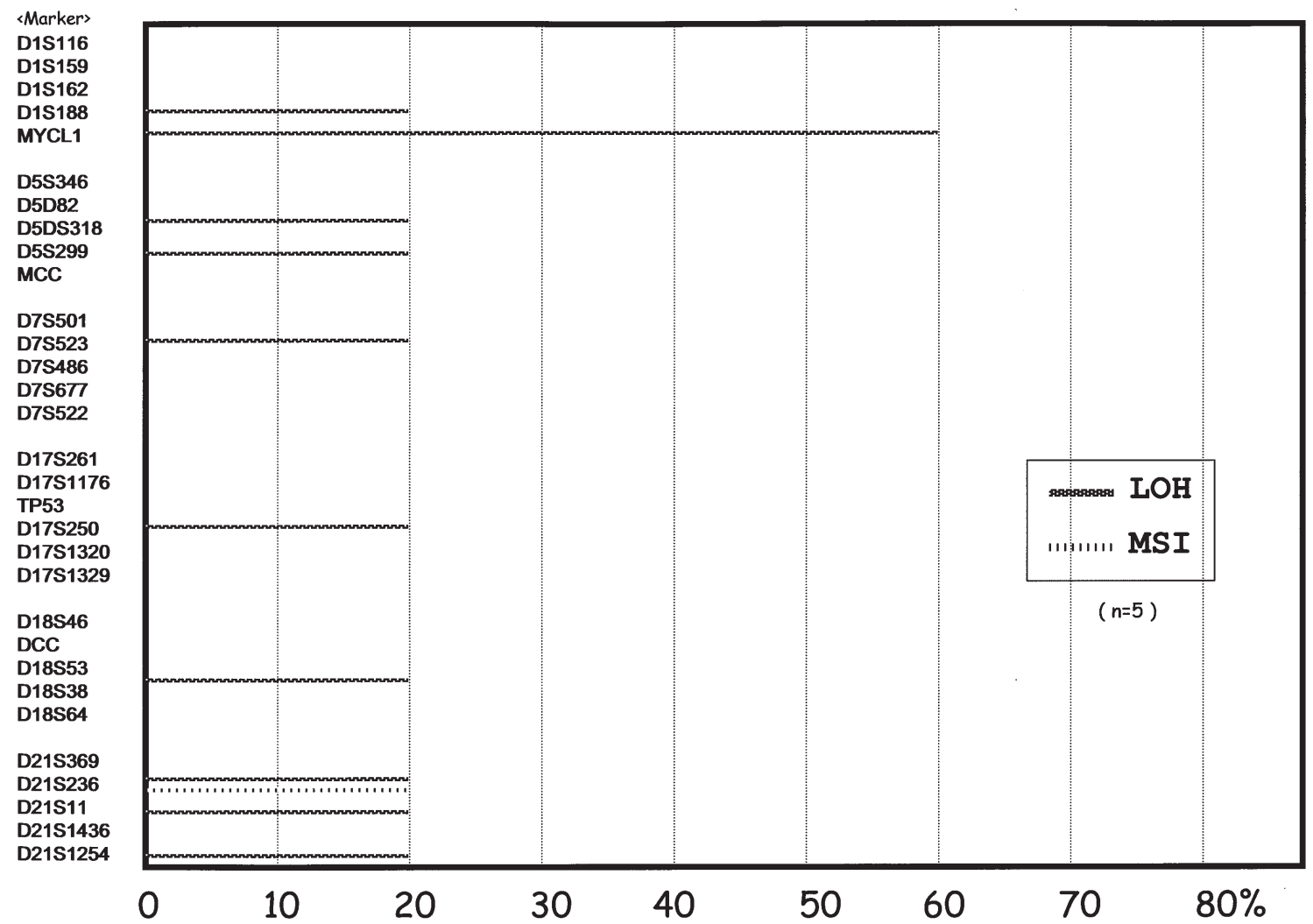

B

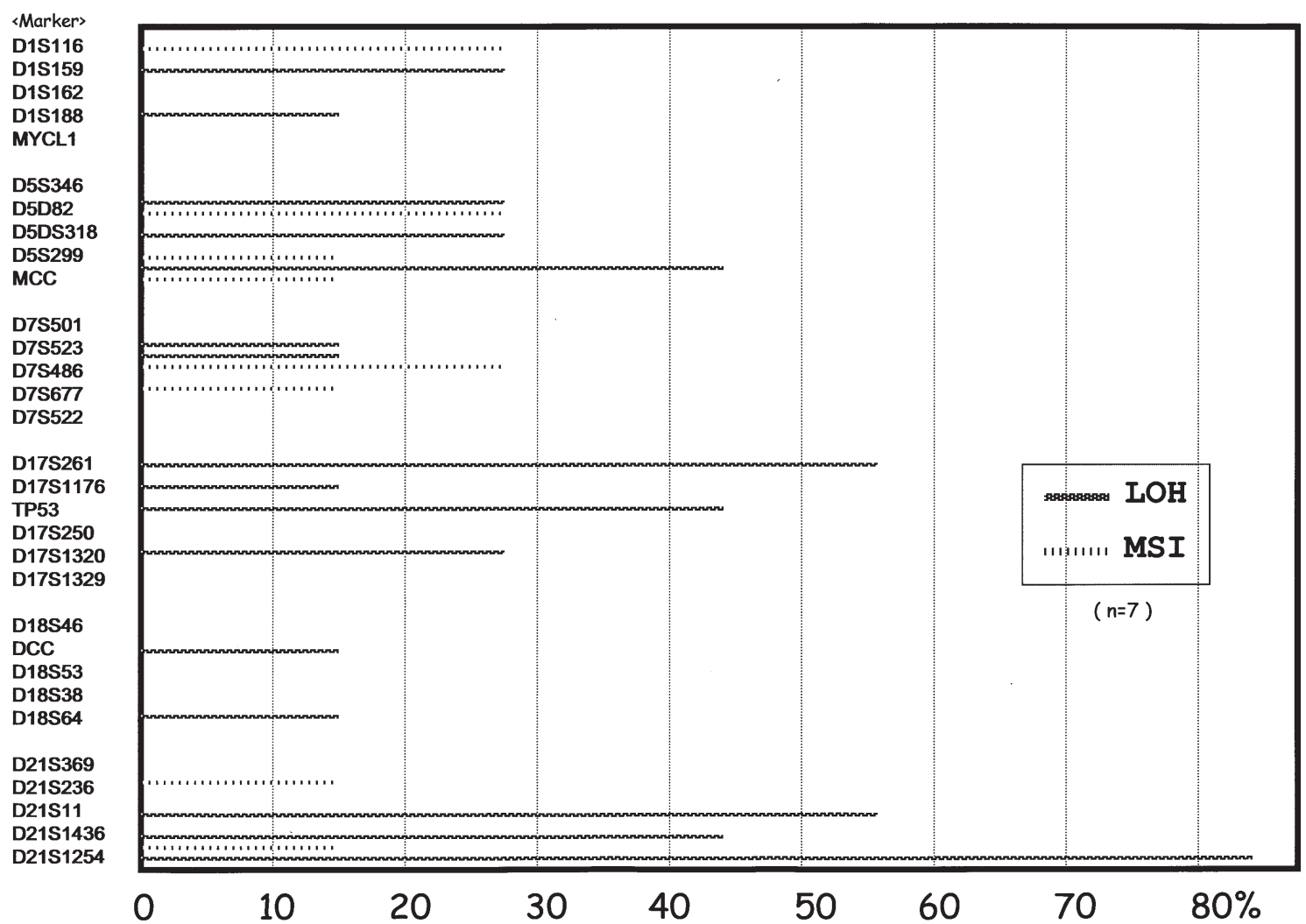

Figure 3. (A) Frequency of the deletion of chromosome 1p, 5q, 7q, 17p, 17q, 18q and 21q in Hp-negative well-differentiated adenocarcinoma with LOH or MSI. (B) Frequency of the deletion of chromosome 1p, 5q, 7q, 17p, 17q, 18q and 21q in Hp-negative poorly-differentiated adenocarcinoma with LOH or MSI.

additional bands in the tumor sample that were not observed in the corresponding normal sample or in cases with a band shift in the tumor sample that contrasted with those of the corresponding normal bands (Fig. 1).

\section{Results}

In the groups $\mathrm{A}, \mathrm{B}$ and $\mathrm{C}$, at least one structural chromosomal aberration such as LOH and MSI was identified. These 
A

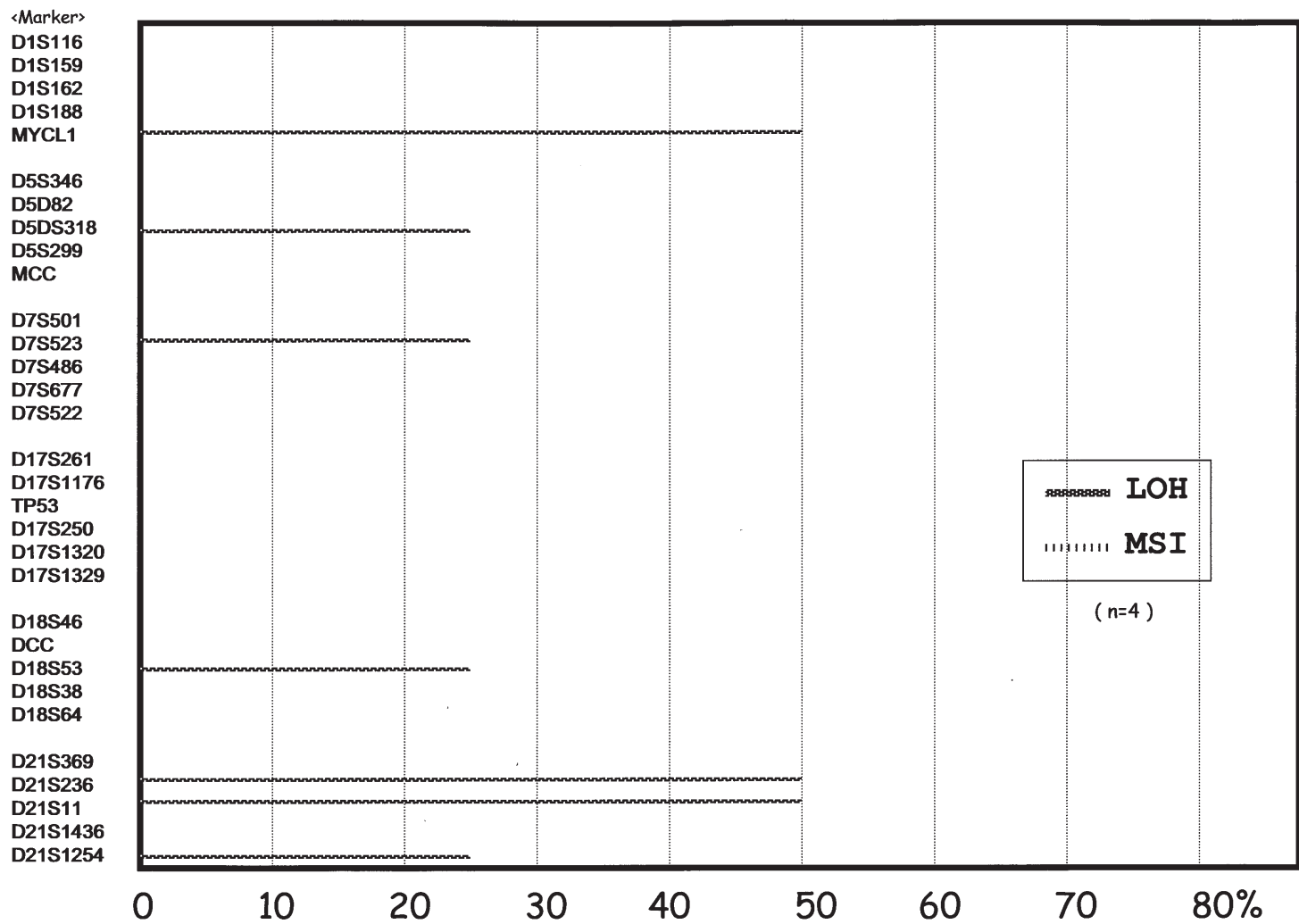

$\mathbf{B}$

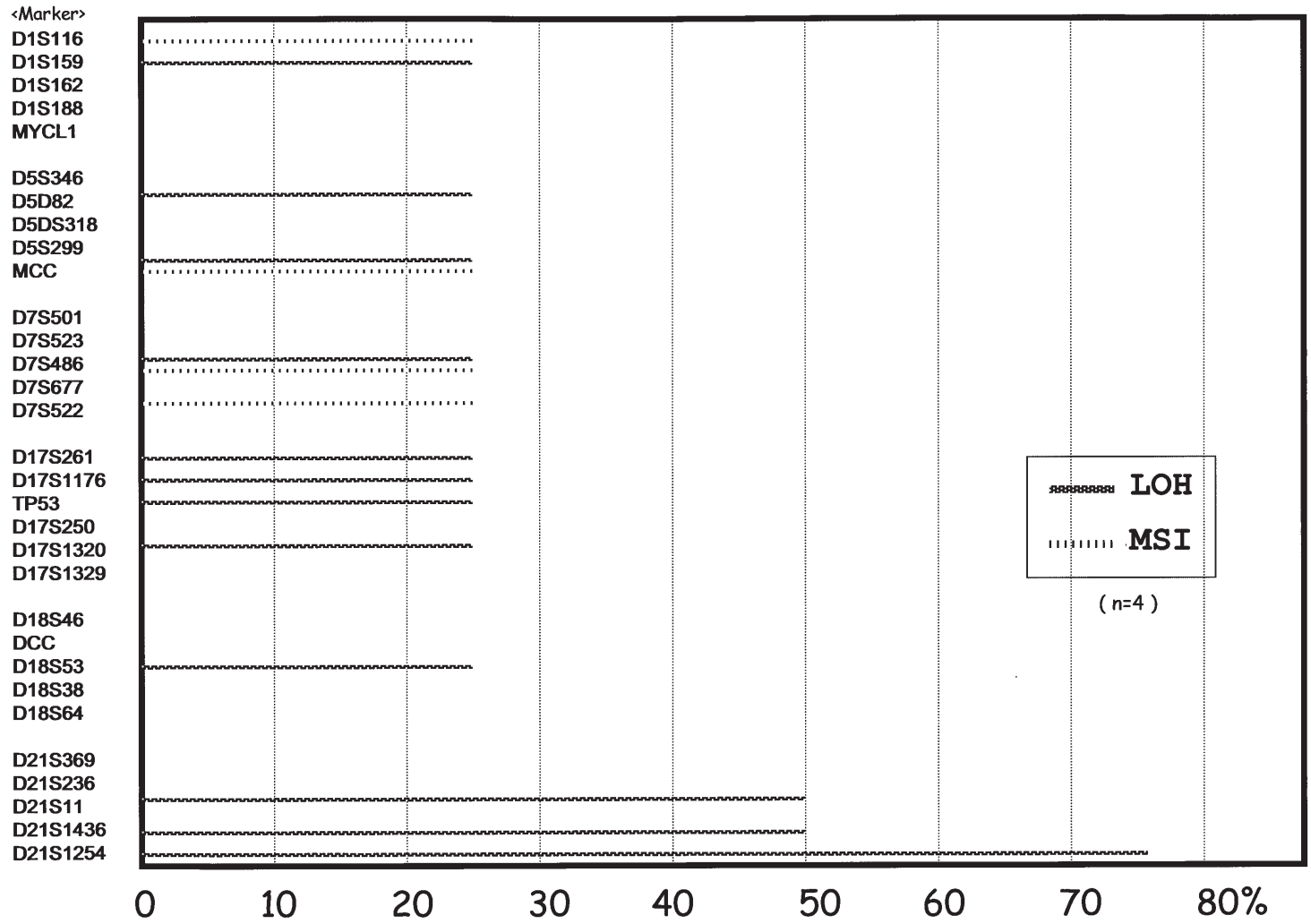

Figure 4. (A) Frequency of the deletion of chromosome 1p, 5q, 7q, 17p, 17q, 18q and 21q in Hp-negative well-differentiated adenocarcinoma with LOH or MSI following eradication therapy. (B) Frequency of the deletion of chromosome 1p, 5q, 7q, 17p, 17q, 18q and 21q in Hp-negative poorly-differentiated adenocarcinoma with LOH or MSI following eradication therapy.

abnormalities were not associated with the histological type of gastric cancer or any background variable such as Hp infection (Tables II and III). In each of the above groups, structural chromosomal aberrations tended to be more marked in poorly differentiated gastric cancer cases than in those with well-differentiated gastric cancer (Figs. 2A and B, 3A and B, and $4 \mathrm{~A}$ and $\mathrm{B}$ ). In terms of structural chromosomal aberrations, there was no marked difference between Group A and either 
Table II. The changes of chromosome 1p, 5q, 7q, 17p, 17q, 18q and 21q in the regionof Hp-positive and Hp-negative gastric cancers with LOH or MSI.

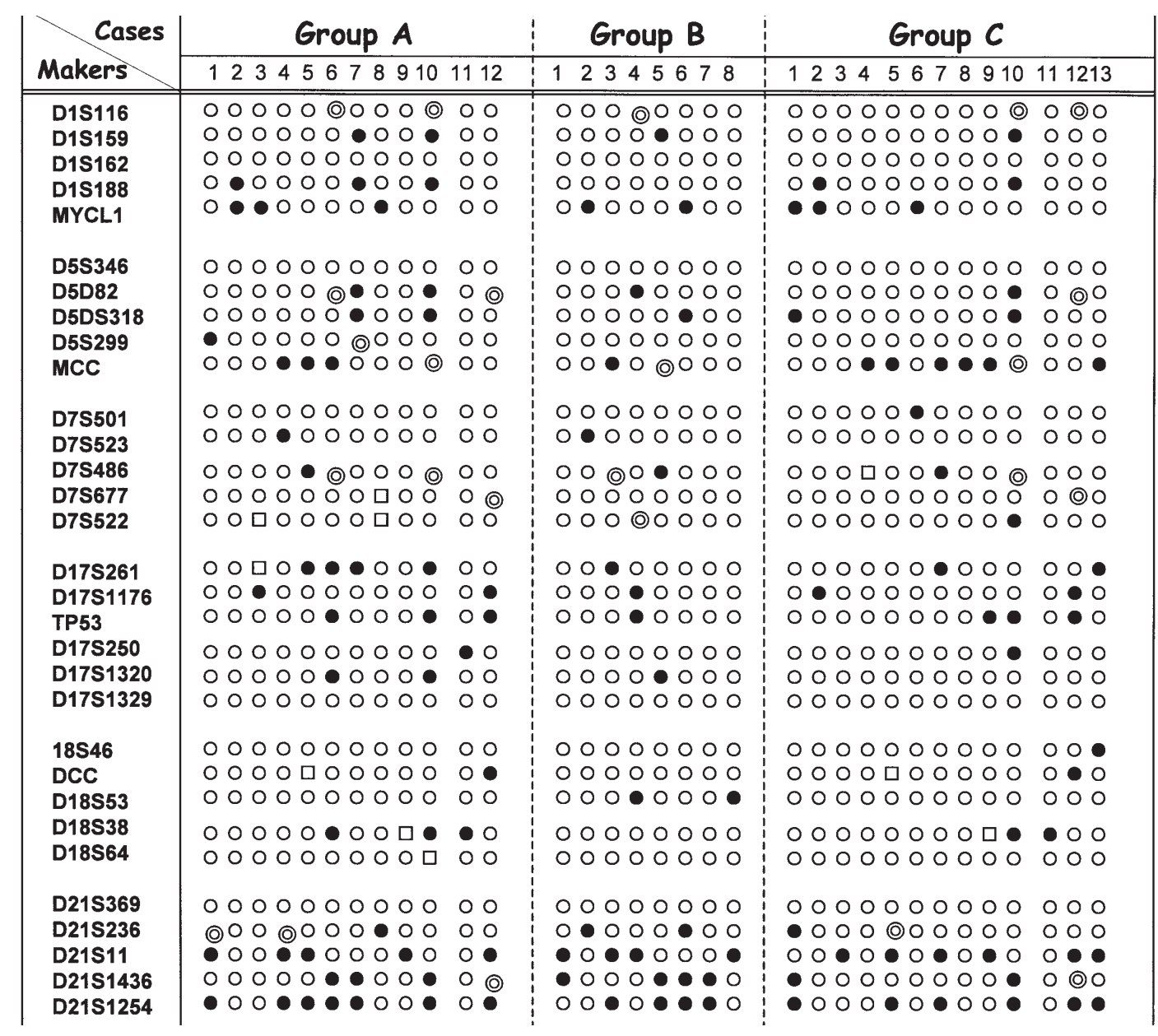

Groups A, B and C indicate Hp-negative cases, Hp-negative incidence cases following eradication therapy and Hp-positive cases, respectively. Cases 1 to 3,8 and 11 are well-differentiated adenocarcinomas, and the cases 4 to 7,9 to 10 and 12 are poorly-differentiated adenocarcinomas in group A. Cases 1 to 2, 6 and 8 are well-differentiated adenocarcinomas, and the cases 3 to 5 and 7 are poorlydifferentiated adenocarcinomas in group B. Cases 1 to 6 and 8 are well-differentiated adenocarcinomas, and the cases of 7 and 9 to 13 are poorly-differentiated adenocarcinomas in group C. $\bullet, \bullet$, a circle within a circle, and $\square$ indicate retention of heterozygosity (ROH), LOH, MSI and not informative (NI), respectively.

Group B or C (Table III). In Group D, no change in chromosomal structure was observed following Hp eradication as compared to the pre-eradication structure (Table III).

\section{Discussion}

Gene mutation is essential for carcinogenesis (1-7). The onset of gastric and other cancers is thought to take place in steps in the presence of gene mutations combined with various environmental factors such as dietary style. Hp infection has been regarded as an important factor associated with the onset of gastric cancer (9-13), and Hp eradication has been conducted to prevent the onset of gastric cancer $(23,24)$. However, many cases of gastric cancer occurring after Hp eradication have been reported $(14-16,24)$, and the extent to which Hp eradication can suppress the onset of gastric cancer and the site involved in $\mathrm{Hp}$ infection in gastric carcinogenesis are unknown. The onset mechanism of Hp-negative gastric cancer is also unknown. There are no reports as to whether or not Hp-negative gastric cancers occur in unique features of structural chromosomal aberrations in comparison with Hppositive gastric cancers. When discussing the mechanism of carcinogenesis, it is important to determine whether or not $\mathrm{Hp}$ infection induces gene mutations. In the present study, structural chromosomal aberrations such as LOH and MSI were also identified in Hp-negative gastric cancer patients, as in Hp-positive gastric cancer patients, and there was no evident difference in these abnormalities between the Hpnegative and $\mathrm{Hp}$-positive groups. Eradication of $\mathrm{Hp}$ was also shown to be unlikely to affect structural chromosomal aberrations. These two findings from the present study are clinically significant. Factors involved in carcinogenesis can be roughly divided into genetic and various additive/ synergistic factors (e.g., environmental factors). In view of the present results, it seems probable that $\mathrm{Hp}$ infection is involved in the mechanism of gastric carcinogenesis as an additive/synergistic factor rather than as a factor affecting the genes. Various additive/synergistic factors involved in carcinogenesis are known, in addition to Hp. We consider the results of our present study to also allow us to explain why gastric 
Table III. The changes of chromosome 1p, 5q, 7q, 17p, 17q, $18 \mathrm{q}$ and $21 \mathrm{q}$ in the region of pre- and post-eradication therapy of gastric cancers with LOH or MSI.

\begin{tabular}{|c|c|c|c|c|c|c|c|}
\hline \multirow{3}{*}{ Cases } & \multicolumn{7}{|c|}{ Group D } \\
\hline & \multicolumn{3}{|c|}{ Pre-eradication } & \multicolumn{4}{|c|}{ Post-eradication } \\
\hline & 12 & 345 & 67 & & 2 & 345 & 67 \\
\hline D1S116 & 00 & 0 (2) & 00 & $\mathrm{O}$ & 0 & 0 ○ & O O \\
\hline D1S159 & 00 & 000 & 00 & & 0 & 000 & 00 \\
\hline D1S162 & ○ 0 & 000 & 00 & $\square$ & 0 & 000 & 00 \\
\hline $\begin{array}{l}\text { D1S188 } \\
\text { MYCL1 }\end{array}$ & $\begin{array}{ll}0 & 0 \\
0 & 0\end{array}$ & $\begin{array}{lll}0 & 0 & 0 \\
0 & 0 & 0\end{array}$ & $\begin{array}{ll}0 & 0 \\
0 & 0\end{array}$ & & $\begin{array}{l}0 \\
0\end{array}$ & $\begin{array}{lll}0 & 0 & 0 \\
0 & 0 & 0\end{array}$ & $\begin{array}{ll}0 & 0 \\
0 & 0\end{array}$ \\
\hline D5S346 & 00 & 000 & 00 & 0 & 0 & 000 & 00 \\
\hline D5D82 & 00 & 000 & 00 & 0 & 0 & 000 & 00 \\
\hline D5DS318 & 00 & - 00 & 00 & $\mathrm{O}$ & 0 & - 00 & 00 \\
\hline D5S299 & 00 & 000 & 00 & O & $\mathrm{O}$ & 000 & ० 0 \\
\hline MCC & $0 \bullet$ & $0 \bullet \bullet$ & O O & O & - & $0 \bigcirc 0$ & 00 \\
\hline D7S501 & 00 & 000 & 00 & 0 & 0 & 000 & O o \\
\hline D7S523 & 00 & 000 & 00 & 0 & 0 & 000 & 00 \\
\hline D7S486 & 00 & 000 & 00 & 0 & 0 & 000 & 00 \\
\hline D7S677 & 00 & 000 & 00 & 0 & 0 & 000 & 00 \\
\hline D7S522 & 00 & 000 & 00 & 0 & 0 & 000 & 00 \\
\hline D17S261 & 00 & 000 & O O & 0 & 0 & 000 & ० 0 \\
\hline D17S1176 & 00 & 000 & - 0 & 0 & 0 & 000 & - 0 \\
\hline TP53 & 00 & 000 & 00 & 0 & 0 & 000 & 00 \\
\hline D17S250 & 00 & 000 & 00 & 0 & 0 & 000 & 00 \\
\hline D17S1320 & 00 & 000 & 00 & $\square$ & O & 000 & 00 \\
\hline D17S1329 & 00 & 000 & O O & $\square$ & O & 000 & 00 \\
\hline $18 S 46$ & 00 & $0 \square 0$ & 00 & 0 & O & 000 & 00 \\
\hline DCC & 00 & $O \square O$ & 00 & O & O & 000 & 00 \\
\hline D18S53 & 00 & $O \square O$ & 00 & 0 & 0 & 000 & 00 \\
\hline D18S38 & 00 & $O \square 0$ & 00 & 0 & 0 & 000 & 00 \\
\hline D18S64 & 00 & $0 \square 0$ & 00 & & 0 & 000 & 00 \\
\hline D21S369 & 00 & 000 & 00 & 0 & 0 & 000 & 00 \\
\hline D21S236 & - 0 & 000 & 00 & - & 0 & 000 & 00 \\
\hline D21S11 & 00 & $00 \bullet$ & 00 & O & 0 & $00 \bullet$ & 00 \\
\hline D21S1436 & 00 & $\bullet$ & $0 \bullet$ & 0 & 0 & - & 00 \\
\hline D21S1254 & - 0 & $\circ \bullet \bullet$ & $0 \bullet$ & - & 0 & $0 \bullet$ & $0 \bullet$ \\
\hline
\end{tabular}

This group indicates pre- and post-eradicated therapy cases of gastric cancers infected with Hp. Cases 1 to 3 and 6 to 7 are welldifferentiated adenocarcinomas, and the cases 4 to 5 are poorlydifferentiated adenocarcinomas. $\odot, \bullet$, double circle, and $\square$ indicate retention of heterozygosity (ROH), $\mathrm{LOH}, \mathrm{MSI}$ and not informative (NI), respectively.

cancer occurs even after Hp eradication. As demonstrated in previous epidemiological studies of patients with gastric cancer, it is highly probable that Hp serves as an important factor involved in the onset of gastric cancer. According to our view, it is possible to reduce the incidence of gastric cancer by eradicating $\mathrm{Hp}$ but it is difficult to completely prevent its onset by means of $\mathrm{Hp}$ eradication. It cannot be said with certainty that $\mathrm{Hp}$ infection had not occurred in all of $\mathrm{Hp}$ negative gastric cancer patients. We cannot rule out the possibility that some $\mathrm{Hp}$ cases were negative at the time of gastric cancer onset but had suffered Hp infection previously. As far as $\mathrm{Hp}$ eradication therapy is concerned, a clinically significant issue remains; identification of the stage of $\mathrm{Hp}$ infection at which $\mathrm{Hp}$ eradication is expected to allow greater suppression of gastric cancer onset.

\section{Acknowledgements}

This work was supported by research subsidies from Takeda Pharmaceutical Industry Corporation, Japan.

\section{References}

1. El-Hamidi A, Hamoudi RA, Kocjan G and Du Mo: Cervical intraepithelial neoplasia: prognosis by combined $\mathrm{LOH}$ analysis of multiple loci. Gynecol Oncol 94: 671-679, 2004

2. Palmirotta R, Matera S, Curia MC, Aceto G, El-Zhobi B, Verginelli F, Guadagni F, Casale V, Stigliano V, Messerini L, Mariani-Costantini R, Battista P and Cama A: Correlations between phenotype and microsatellite instability in HNPCC: implications for genetic testing. Fam Cancer 3: 117-121, 2004

3. Fauth C, O'Hare MJ, Lederer G, Jat PS and Speicher MR: Order of genetic events is a critical determinant of aberrations in chromosome count and structure. Genes Chromosomes Cancer 40: 298-306, 2004.

4. Heidenblad M, Schoenmakers EF, Jonson T, Gorunoval L, Veltman JA, van Kessel AG and Hoglund M: Genome-wide array-based comparative genomic hybridization reveals multiple amplification targets and novel homozygous deletions in pancreatic carcinoma cell lines. Cancer Res 1:64: 3052-3059, 2004

5. Nishimura T, Nishida N, Itoh T, Kuno M, Minata M, Komeda T, Fukuda Y, Ikai I, Yamaoka Y and Nakao K: Comprehensive allelotyping of well-differentiated human hepatocellular carcinoma with semiquantitative determination of chromosomal gain or loss. Genes Chromosomes Cancer 35: 329-339, 2002.

6. Gunawan B, Huber W, Holtrup M, von Heydebreck A, Efferth T, Poustka A, Ringert RH, Jakse G and Fuzesi L: Prognostic impacts of cytogenetic findings in clear cell renal cell carcinoma: gain of 5q31-qter predicts a distinct clinicalphenotype with favorable prognosis. Cancer Res 61: 7731-7738, 2001.

7. Watanabe T, Wang X-L, Miyakawa A, Shiba M, Imai Y, Sato T and Tanzawa $\mathrm{H}$ : Mutation state of tumor suppressor genes (DCC, DPC4) and alteration on chromosome 18q21 in human oral cancer. Int J Oncol 11: 1287-1290, 1997.

8. Ohara T, Kasanuki J, Morishita T, Yamamoto N, Shibahara T, Suzuki H, Masaoka T, Nishizawa T and Hibi T: Evaluation of the role of Helicobacter pylori as a promoter of gastric cancer from the viewpoint of structural chromosomal aberration. Aliment Pharmacol Ther Symp Ser 2: 111-119, 2006.

9. Leung WK: Helicobacter pylori and gastric neoplasia. Contrib Microbiol 13: 66-80, 2006.

10. Hamilton JP and Meltzer SJ: A review of the genomics of gastric cancer. Clin Gastroenterol Hepatol 4: 416-425, 2006.

11. Pellicano R, Mladenova I, Martinotti, Fagoonee S and Rizzetto M: Gastric cancer and Helicobacter pylori: an interdisciplinary point of view. Minerva Med 97: 31-38, 2006.

12. Matysiak-Budnik T and Megraud F: Helicobacter pylori infection and gastric cancer. Eur J Cancer 42: 708-718, 2006.

13. Kim N, Cho SI, Yim JY, Kim JM, Lee DH, Park JH, Kim JS, Jung HC and Song IS: The effects of genetic polymorphisms of IL-1 and TNF-A on Helicobacter pylori-induced gastroduodenal diseases in Korea. Helicobacter 11: 105-112, 2006.

14. Onoda N, Katsuragi K, Sawada T, Maeda K, Mino A, Ohira M, Ishikawa T, Wakasa K and Hirakawa K: Efficacy of Helicobacter pylori eradication on the chronic mucosal inflammation of the remnant stomach after distal gastrectomy for early gastric cancer. J Exp Clin Cancer Res 24: 515-521, 2005.

15. Tsai CJ, Herrera-Goepfert R, Tibshirani RJ, Yang S, Mohar A, Guarner J and Parsonnet J: Changes of gene expression in gastric preneoplasia following Helicobacter pylori eradication therapy. Cancer Epidemiol Biomarkers Prev 15: 272-280, 2006.

16. Wong BC, Lam SK, Wong WM, Chen JS, Zheng TT, Feng RE, Lai KC, Hu WH, Yuen ST, Leung SY, Fong DY, Ho J, Ching CK and Chen JS: China Gastric cancer Study Group: Helicobacter pylori eradication to prevent gastric cancer in a high-risk region of China: a randomized controlled trial. JAMA 29: 187-194, 2004

17. Fujiwara Y, Osugi H, Morimura K, Takemura M, Lee S, Hirohashi K, Fukushima S and Suehiro S: Suppressive effect of CPT-11 on rat esophageal tumorigenesis induced by N-nitrosomethylbenzylamine. Oncol Rep 12: 1169-1176, 2004. 
18. Meeker AK, Hicks JL, lacobuzio-Donahue CA, Montgomery EA, Westra WH, Chan TY, Ronnett BM and De Marzo AM: Telomere length abnormalities occur early in the initiation of epithelial carcinogenesis. Clin Cancer Res 10: 3317-3326, 2004.

19. Russell SE and McCluggage WG: A multistep model for ovarian tumorigenesis: the value of mutation analysis in the KRAS and BRAF genes. J Pathol 203: 617-619, 2004.

20. World Health Organization International Histological Classification of Tumor; histological typing of tumors. No. 4. WHO, Geneva, 1971.

21. Maniatis T, Fritsch EF and Sambrook J: Molecular Cloning; A Laboratory Manual. 1st edition, Cold Spring Harbor Laboratory Press, Cold Spring Harbor, New York, pp280-281, 1982.
22. Komiya A, Suzuki H, Aiba S, Yatani R and Shimazaki J: Mutational analysis of CDKN2 (CDK4I/MTS1) gene in tissues and cell lines of human prostate cancer. Jpn J Cancer Res 86: 622-625, 1995.

23. Uemura N, Mukai T, Okamoto S, Yamaguchi S, Mashiba H, Taniyam K, Sasaki N, Haruma K, Sumii K and Kajiyama G: Effect of Helicobacter pylori eradication on subsequent development of cancer after endoscopic resection of early gastric cancer. Cancer Epidemiol Biomarkers Prev 6: 639-642, 1997.

24. Tsuji S, Tsujii M, Murata H, Nishida T, Komori M, Yasumaru M, Ishii S, Sasayama Y, Kawano S and Hayashi N: Helicobacter pylori eradication to prevent gastric Cancer: Underlying molecular and cellular mechanisms. World J Gastroenterol 12: 1671-1680, 2006. 